\title{
Properties of the Apathy Scale (AS) for use on Parkinson's patients
}

\author{
Marcos Serrano-Dueñas ${ }^{1,2^{\star}}$, Pablo Martínez-Martín ${ }^{3}$, Tamara Merchán ${ }^{2}$, Rosaura Bravo², \\ Maite Serrano ${ }^{2}$

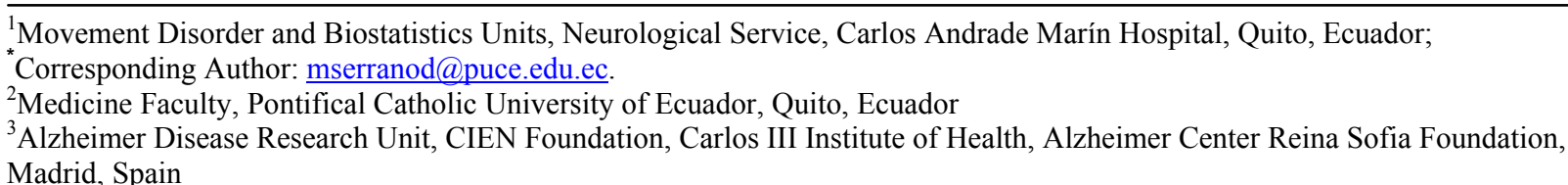

Received 5 February 2013; revised 11 March 2013; accepted 20 March 2013

Copyright (C) 2013 Marcos Serrano-Dueñas et al. This is an open access article distributed under the Creative Commons Attribution License, which permits unrestricted use, distribution, and reproduction in any medium, provided the original work is properly cited.

\begin{abstract}
Parkinson's Disease is a neurodegenerative disorder characterized by motor, autonomic, and neuropsychiatric symptoms, among the latter, apathy has been found to be present in up to $70 \%$ of patients. The main objective of the present study was to assess the psychometric properties of the Apathy Scale for evaluation of Ecuadorian patients with Parkinson's. This was a cross sectional study, with re-test. There were 73 women $(34.5 \%)$ in the final sample of 211 patients. Mean age was $67.5 \pm 10.2$ years, mean length of illness was $7.1 \pm 5.5$ years, and the mean Idopa dose was $656.1 \pm 292.7 \mathrm{mg} /$ day. The mean Apathy Scale score was $12.7 \pm 7.1$. Reliability: The Guttman's $\lambda$ obtained was 0.89 . The SEM was 2.34 for the AS. The ICC using an absolute agreement definition was: ICC $=0.78$ [(95\% IC $0.73-0.82) f=4.96 ; p \leq 0.000]$. Discriminative validity, analyzed with the KruskalWallis statistic and using H\&Y stages as segmentation variable registered an $X(2)$ value of $p<$ 0.0001 . In conclusion the Apathy Scale proved to have suitable metric attributes in this specific PD patient sample: internal consistency, reliability, stability, and convergent and known-groups validity.
\end{abstract}

Keywords: Parkinson's Disease; Apathy Associated with Parkinson's Disease; Apathy Scale; Metric Properties

\section{INTRODUCTION}

Parkinson's disease (PD) is a chronic, progressive neu- rodegenerative disease that causes motor symptoms (rest tremor, bradykinesia, rigidity and loss of postural reflexes); neuropsychiatric symptoms (depression, anxiety, dementia, apathy, psychosis); autonomic symptoms (urinary incontinence, orthostatic hypotension and erectile dysfunction, among others); and a set of signs and symptoms that do not fit into the previous groups: dysphagia, drooling, seborrhea. Its epidemiology shows an overall prevalence of 1 out of every 1000 inhabitants, and a specific prevalence of 1 out of every 100 inhabitants in the $65+$ age group [1].

Apathy has been conventionally defined as the absence or insufficiency of sensation, emotion, interest, or concern. Conceptually, it is closely related to emotionality and motivation [2], may present as a syndrome in itself or as part of other neuropsychiatric disorders, such as depression, despair, abulia, and dementia, in particular [3].

It is thought that apathy develops as a result of the disruption of auto-activation processes, resulting in an inability to think or act for oneself or on one's own, while still maintaining a relatively unimpaired ability to respond or react to external prompting or stimuli $[4,5]$.

Marin [3] was the first to present diagnostic criteria for apathy centered on lack of motivation unattributable to mental deterioration, emotional distress, or diminished level of consciousness, and manifesting as diminished goal-directed behavior, diminished goal-directed cognition, and diminished concomitants of goal-directed behavior.

Some diagnostic criteria have recently been published [6]. The Movement Disorder Society (MDS) Task Force to Assess the Clinimetric Properties of Apathy and Anhedonia Scales in PD patients [7] identified four apathy rating scales: the Apathy Evaluation Scale (AES); the abbreviated version of the AES, known as the Apathy Scale 
(AS); the Apathy Inventory (AI); and the Lille Apathy Rating Scale (LARS). The AS, AI, and LARS were specifically developed for patients with PD, but only the AS meets criteria to be "recommended".

The main objective of the present study was to assess the psychometric properties of the AS [8] for evaluation of Ecuadorian patients with PD.

\section{METHOD}

\subsection{Design}

Cross sectional study, with re-test.

\subsection{Patients}

Consecutive patients with diagnosis of PD regularly followed-up at the Movement Disorders Unit, Neurology Department, Carlos Andrade Marín Hospital (Quito, Ecuador), according to the United Kingdom PD Society Brain Bank criteria [9]. Exclusion criteria were: cognitive impairment more than dubious or slight, evaluated by the Short Portable Mental Status Questionnaire of Pfeiffer (SPMSQ; cutoff 5/6) [10]; neurological impairment or disability due to any condition other than PD (e.g., hemiplegia or blindness) or psychiatric comorbidity (depression) that hindered appropriate evaluation according to the objective of the study.

The study was approved by the (Institutional Review Board) HCAM Teaching and Research Administrative Office. Informed consent was obtained from all patients.

\subsection{Assessment}

The AS [8] is based on the Apathy Evaluation Scale (AES) by Marin et al., [11] and consists of 14 of the 18 original items. In the AS, each question is read by the examiner and has four options of response: "not at all", "slightly", "some", or "a lot". Scores range from 0 to 42 ; higher scores indicate more severe apathy. Items 1 to 8 score: not at all $=3$ points; slightly $=2$; some $=1$; a lot $=$ 0 ; items 9 to 14 score: not at all $=0$; slightly $=1$; some $=$ 2 ; a lot $=3$.

General demographic and clinical information was collected from each patient. In addition to the AS, the following assessment instruments were applied: Short Parkinson's Evaluation Scale (SPES/SCOPA) for evaluation of motor dysfunction [12]; Hoehn \& Yahr for staging (H\&Y); Schwab \& England Activities of Daily Living Scale (S\&E) for disability; Hospital Anxiety and Depression Scale (HADS) for mood disorder [13]; Parkinson's Impact Scale (PIMS) for health-related quality of life status (HRQoL) [14]; and Clinical Impression of Severity Index (CISI-PD) for global evaluation [15]. All the patients were evaluated in the ON state and the same day.

A cut-off point $\geq 14$ from the total score of the AS was used to dichotomize the sample into apathetic and nonapathetic patients [8].

\subsection{Statistical Analysis}

The following attributes were explored:

Data was considered acceptable [16]. Observed scores should cover the range of the scale scores and mean should be near the theoretical median (an arbitrary limit $10 \%$ for the difference was proposed) [17]. Floor and ceiling effect must not exceed $15 \%$ and skewness should be between -1 to +1 [18].

Internal consistency. The inter-item correlation matrix (Spearman rho) (limits: $\geq 0.20$ to $\leq 0.75$ ) [19] and the item homogeneity index (threshold, 0.30) were obtained [20]. In addition, the corrected Item-total correlation was determined. As coefficient of internal consistency, the Guttman's lambda $(\lambda)$ was determined because assumptions for use of Cronbach's alpha were not met [21]. Agreement (test-retest agreement). Seventy-one patients, randomly chosen, repeated the AS assessment 6 days after the first evaluation (range: from 4 to 9 days). Test-retest agreement was analysed by mean of the intraclass correlation coefficients (ICC) using an absolute agreement definition (2-way, random effects, intraclass correlation coefficient).

Precision. The standard error of measurement (SEM) for the AS was calculated ( $\left.\mathrm{SEM}=\mathrm{SD}^{*} \sqrt{[1-\mathrm{ICC}]}\right)$ [22].

Spearman rank correlation coefficient was used to determine the association between the AS and other measures in the study. A close association $(\mathrm{rS} \geq 0.50)$ [23], was hypothesized between AS and HADS, a moderate $(\mathrm{rS}=0.35-0.50)$ or low $(\mathrm{rS} \leq 0.34)$ correlation was expected between AS and the other scales. To analyze known-groups validity the $\mathrm{H} \& \mathrm{Y}$ stages were used for stratification and the Kruskal-Wallis (KW) test for statistical analysis. We also used a HADS score cut-off $\geq 11$, to consider the patients anxious or depressed [24] and AS score was compared between groups with and without the respective disorder applying the Mann-Withney test. For both analyses, a $p$ value $\leq 0.05$ was accepted as significant [25].

\section{RESULTS}

There were 73 women (34.5\%) in the final sample of 211 patients, distributed according to $\mathrm{H} \& \mathrm{Y}$ stages as follows: 29 (13.7\%) in Stage I; $47(22.2 \%)$ in II; 98 $(46.4 \%)$ in III; and $37(17.7 \%)$ in IV, including two Stage $\mathrm{V}$ patients. Mean age was $67.5 \pm 10.2$ years, mean length of illness was $7.1 \pm 5.5$ years, and the mean 1-dopa dose was $656.1 \pm 292.7 \mathrm{mg} /$ day. The mean AS score was 12.7 \pm 7.1 .

Classifying the patients according to the AS and the HADS, we found 33 patients with apathy alone (15.7\%); 
121 patients with neither apathy nor depression nor anxiety $(57.3 \%) ; 42$ patients with apathy and depression and/or anxiety (19.9\%); finally, 15 patients with depression and/or anxiety without apathy $(7.1 \%)$. There were no missing data. The difference between the mean and the median in the AS was 1.78 points. The floor and ceiling effects were 1.42 and 2.36 , respectively; skew and kurtosis were 0.65 and -0.26 , respectively (Table 1).

Internal consistency: Analysis of the correlation matrix showed the average interitem correlation was located between 0.21 and 0.37 , with the exception of items 3 $(-0.066)$ and $4(-0.145)$. The item homogeneity index was 0.21 . Reliability: The Guttman's $\lambda$ obtained was 0.89 . When analyzing AS behavior-specifically the Guttman's $\lambda$ value - we observed that when the item was eliminated, items 3 and 4 would allow raising the reliability index to 0.9 (Table 2).

The SEM was 2.34 for the AS: values were 2.94 in H\&Y Stage 1; 1.85 in Stage 2; 1.96 in Stage 3; and 2.65 in Stage 4.

Agreement (test-retest agreement). Seventy-one patients repeated the AS assessment 6 days after the first evaluation (range: from 4 to 9 days). The ICC using an absolute agreement definition was: ICC $=0.78$ [(95\% IC $0.73-0.82) \mathrm{f}=4.96 ; \mathrm{p} \leq 0.000]$.

When analyzing the correlations of the AS with the Spearman's rho statistic, we obtained values of 0.49 with the HADS anxiety total, 0.48 with the depression section of that same scale, and 0.56 with the PIMS. The values were lower with the other tools.

Discriminative validity (Known-groups validity), analyzed with the Kruskal-Wallis statistic and using H\&Y stages as segmentation variables-registered an $\mathrm{X}(2)$ value of 22.68 $=\mathrm{p}<0.0001$ (Table 3).

Using the HADS (a cut-off $\geq 11$, to consider the patients anxious or depressed), the difference between groups was significant $(\mathrm{p} \leq 0.001)$ (Table 4).

\section{DISCUSSION}

The data quality obtained from the AS is good, and only the difference between the mean and the median $(1.78)$ is outside the $(-1-+1)$ range. There was no floor or ceiling effect, and the skew and kurtosis fell within accepted values. AS reliability was measured according to internal consistency and the reliability index and obtained optimal values (Guttman's $\lambda=0.89$ ). In the first validation study [8] it showed a Cronbach's $\alpha$ value of 0.76 . The scale would improve if we were to eliminate Items 3 and 4 ("Are you concerned about your condition?" "Do you put much effort into things?") from this study sample. These items obtained the lowest correlation values. Moreover, the reliability coefficient improves if they are eliminated.

Convergent validity showed appropriate values when correlated with the PIMS (Spearman's rho of 0.56) and with the HADS anxiety and depression subscales (Spearman's rho of 0.498 and 0.485 ), which were higher than others reported [26], even though in general it is reportedly comparable to other instruments for evaluating depression and anxiety. These correlations are similar to others obtained. The highest value was obtained vis-à-vis the PIMS, which would indicate that apathy is a quality-of-life determinant [27].

Known-groups validity demonstrated that there were

Table 1. Descriptives of the sample (N (f/m) 211 (73/138)).

\begin{tabular}{|c|c|c|c|c|c|c|}
\hline & Median & Mean \pm SD & Minimum & Maximum & Skewness & Kurtosis \\
\hline Age (years) & 68 & $67.5 \pm 10.2$ & 38 & 86 & -0.08 & -0.4 \\
\hline Disease (years) & 6 & $7.1 \pm 5.5$ & 0,2 & 25 & 1.3 & 1.5 \\
\hline Years wit 1-dopa & 4 & $5.3 \pm 4.7$ & 0 & 20 & 1 & 0.6 \\
\hline Doses of 1-dopa (mg/day) & 750 & $656.1 \pm 292.7$ & 0 & 1.550 & 0 & 0 \\
\hline SPES/SCOPA total & 28 & $29.9 \pm 11.1$ & 10 & 61 & 0.6 & 0.1 \\
\hline $\mathrm{S} \& \mathrm{E}$ & 70 & $70.3 \pm 15.6$ & 20 & 90 & -1.1 & 1.2 \\
\hline CISI total & 10 & $10.7 \pm 4.1$ & 3 & 19 & 0.3 & -0.7 \\
\hline SPMSQ & 0 & $1.3 \pm 1.6$ & 0 & 7 & 1.2 & 1.3 \\
\hline HADS anxiety & 8 & $8.3 \pm 4$ & 1 & 17 & 0.3 & -0.6 \\
\hline HADS depression & 7 & $7.2 \pm 4.2$ & 0 & 19 & 0.5 & 0.1 \\
\hline PIMS & 15 & $15.9 \pm 8.8$ & 0 & 35 & 0 & -0.7 \\
\hline AS & 11 & $12.7 \pm 7.1$ & 1 & 31 & 0.6 & -0.2 \\
\hline
\end{tabular}

SPES/SCOPA: Short Parkinson's Evaluation Scale; S\&E: Schwab \& England Activities of Daily Living Scale; CISI: Clinical Impression of Severity Index; SPMSQ: Short Portable Mental Status Questionnaire of Pfeiffer; HADS: Hospital Anxiety and Depression Scale; PIMS: Parkinson's Impact Scale; AS: Apathy Scale. 
Table 2. Metric properties of the AS.

\begin{tabular}{ccc}
\hline & $\begin{array}{c}\text { Corrected item_total } \\
\text { correlation }\end{array}$ & $\begin{array}{c}\text { Guttman's lambda } \\
\text { if item deleted }\end{array}$ \\
\hline Item_1 & 0.51 & 0.87 \\
Item_2 & 0.55 & 0.87 \\
Item_3 & -0.1 & 0.9 \\
Item_4 & -0.23 & 0.91 \\
Item_5 & 0.47 & 0.89 \\
Item_6 & 0.68 & 0.87 \\
Item_7 & 0.72 & 0.86 \\
Item_8 & 0.56 & 0.88 \\
Item_9 & 0.45 & 0.88 \\
Item_10 & 0.49 & 0.87 \\
Item_11 & 0.48 & 0.88 \\
Item_12 & 0.46 & 0.88 \\
Item_13 & 0.38 & 0.89 \\
Item_14 & 0.66 & 0.88 \\
\hline
\end{tabular}

Table 3. Discriminat validity for "known groups" (KruskalWallis test).

\begin{tabular}{lcccccc}
\hline & I & II & III & IV & $\boldsymbol{X}^{(2)}$ & $\mathrm{p} \leq$ \\
\hline $\begin{array}{c}\text { Number of } \\
\text { patients }\end{array}$ & 29 & 47 & 98 & 37 & & \\
$\begin{array}{c}\text { Mean } \pm(\mathrm{SD}) \\
\text { of AS score }\end{array}$ & $11.6 \pm 9$ & $11.2 \pm 5.6$ & $11.8 \pm 6$ & $17.8 \pm 8.1$ & 22.67 & $<0.001$ \\
\hline SD = Standard deviation; $\mathrm{p} \leq 0.05$ as significative. AS: Apathy Scale.
\end{tabular}

Table 4. Discriminat Validity for "known groups". Apathy Scale, total score betwen groups (HADS cut/off). (Mann-Whit-ney Test).

\begin{tabular}{|c|c|c|c|c|c|c|}
\hline & $\begin{array}{c}\text { Non } \\
\text { depression }\end{array}$ & Depression & $\mathrm{p} \leq$ & $\begin{array}{c}\text { Non } \\
\text { anxiety }\end{array}$ & Anxiety & $\mathrm{p} \leq$ \\
\hline $\begin{array}{l}\text { Number of } \\
\text { patients }\end{array}$ & 175 & 36 & & 164 & 47 & \\
\hline $\begin{array}{l}\text { Mean } \pm \\
(\mathrm{SD})\end{array}$ & $10.7 \pm 5.5$ & $22.5 \pm 6.2$ & $<0.001$ & $11.1 \pm 6.2$ & $18.4 \pm 7.3$ & $<0.001$ \\
\hline
\end{tabular}

differences between the degree of apathy and the H\&Y stages (Table 3); this is in keeping with significant dif-ferences found between AS score and illness times and age. This finding is similar to another that has recently been reported [27], where Parkinson patients in the most advanced H\&Y stages showed higher scores for apathy.

When we compared the patient group with apathy to the patient group without apathy or anxiety and/or depression, we found that apathetic patients were, in general, older and had both a longer period of illness and more greatly compromised motor ability, HADS anxiety and depression subscale scores and PIMS scores. These apathy results in Parkinson's patients have not been reported in other publications [28,29].

Analyzing the apathy group in comparison with the apathy and anxiety and/or depression group, the latter had statistically significant higher scores on the AS and in the HADS anxiety and depression subscales (MannWithney test $p=0.001)$, Table 4. These findings are similar to those reported by P. Sockeel et al. [30].

\section{CONCLUSIONS}

In conclusion, apathy is a frequent entity in $\mathrm{PD}$; $35.54 \%$ of patients show signs of it. In a Group of Parkinson's patients, apathy coexists with depression and/or anxiety in $19.9 \%$. Apathy negatively impacts the quality of life of these subjects. The AS proved to have suitable metric attributes in this specific PD patient sample: internal consistency, reliability, stability, and convergent and known-groups validity. Finally, it is important to be able to rely on consensual diagnostic criteria that can provide common elements for studying apathy in PD.

\section{REFERENCES}

[1] Weintraub, D., Comella, C.L. and Horn, S. (2008) Parkinson's disease-Part 3: Neuropsychiatric symptoms. American Journal of Managed Care, 14, S59-S69.

[2] Marin, R.S. (1990) Differential diagnosis and classification of apathy. The American Journal of Psychiatry, 147, 22-30.

[3] Marin, R.S. (1991) Apathy: A neuropsychiatric syndrome. The Journal of Neuropsychiatry \& Clinical Neurosciences, 3, 243-254.

[4] Habib, M. (2004) Athymhormia and disorders of motivation in basal ganglia disease. The Journal of Neuropsychiatry \& Clinical Neurosciences, 16, 509-524.

[5] Schmidt, L., d'Arc, B.F., Lafargue, G., Galanaud, D., Czernecki, V., Grabli, D., et al. (2008) Disconnecting force from money: Effects of basal ganglia damage on incentive motivation. Brain, 131, 1303-1310. doi:10.1093/brain/awn045

[6] Starkstein, S.E. and Leentjens, A.F.G. (2008) The nosological position of apathy in clinical practice. Journal of Neurology, Neurosurgery \& Psychiatry, 79, 1088-1092.

[7] Leentjens, A.F.G., Dujardin, K., Marsh, L., Martinez-Martin, P., Richard, I.H., Starkstein, S.E., et al. (2008) Apathy and anhedonia rating scales in Parkinson's disease: Critique and recommendations. Movement Disorders, 23, 20042014. doi: $10.1002 / \mathrm{mds} .22229$

[8] Starkstein, S.E., Mayberg, H.S., Preziosi, T.J., Andrezejewski, P., Leiguarda, R., Robinson, R.G., et al. (1992) Reliability, validity, and clinical correlates of apathy in Parkinson's disease. The Journal of Neuropsychiatry \& Clinical Neurosciences, 4, 134-139. 
[9] Gibb, W.R.G. and Lees, A.J. (1988) The relevance of the Lewy body to the pathogenesis of idiopathic Parkinson's disease. Journal of Neurology, Neurosurgery \& Psychiatry, 51, 745-752. doi:10.1136/jnnp.51.6.745

[10] Pfeiffer, E. (1975) A short portable mental status questionnaire for the assessment of organic brain deficit in elderly patients. Journal of the American Geriatrics Society, 23, 433-441.

[11] Marin, R.S., Biedrzycki, R.C. and Firingiogullari, S. (1991) Reliability and validity of the apathy evaluation scale. Psychiatry Research, 38, 143-162. doi:10.1016/0165-1781(91)90040-V

[12] Marinus, J., Visser, M., Stiggelbout, A.M., Martin Rabey, J., Martínez-Martín, P., Bonuccelli, U., Kraus, P.H. and van Hilten, J.J. (2004) A short scale for the assessment of motor impairments and disabilities in Parkinson's disease: The SPES/SCOPA. Journal of Neurology, Neurosurgery \& Psychiatry, 75, 388-395.

[13] Zigmond, A.S. and Snaith, R.P. (1983) The hospital anxiety and depresión scale. Acta Psychiatrica Scandinavica, 67, 361-370. doi:10.1111/j.1600-0447.1983.tb09716.x

[14] Calne, S., Schulzer, M., Mak, E., Guyette, C., Rohs, G., Hatchard, S., et al. (1996) Validating a quality of life rating scale for idiopathic Parkinsonism: Parkinson's impact scale (PIMS). Parkinsonism \& Related Disorders, 2, 5561. doi:10.1016/1353-8020(95)00026-7

[15] Martínez-Martín, P., Forjaz, J., Cubo, E., Frades, B. and The ELEP Project Members (2006) Global versus factor related impression of severity in Parkinson's disease: A new clinimetric index (CISI-PD). Movement Disorders, 21, 208-214.

[16] Lamping, D., Schroter, S., Marquis, P., Marrel, A., Duprat, I. and Sagnier, P. (2002) The community-acquired pneumonia symptom questionnaire: A new, patient-based outcome measure to evaluate symptoms in patients with community-acquired pneumonia. Chest, 122, 920-929. doi:10.1378/chest.122.3.920

[17] McHorney, C.A. and Tarlov, A.R. (1995) Individual-patient monitoring in clinical practice: Are available health status surveys adequate? Quality of Life Research, 4, 293307. doi:10.1007/BF01593882

[18] Van der Linden, K., Kragt, J., Klein, M., Van der Ploeg, H., Polman, C., et al. (2005) Psychometric evaluation of the multiple sclerosis impact scale (MSIS-29) for proxy use. Journal of Neurology, Neurosurgery \& Psychiatry, 76, 1677-1681. doi:10.1136/jnnp.2005.065227

[19] Smith, S.C., Lamping, D.L., Banarjee, S., Harwood, R., Foley, B., Smith, P., et al. (2005) Measurement of healthrelated quality of life for people with dementia: Development of a new instrument (DEMQOL) and an evaluation of current methodology. Health Technology Assessment, 9, 16-19.

[20] Eisen, M., Ware Jr., J.E., Donald, C.A. and Brook, R.H.
(1979) Measuring components of children's health status. Medical Care, 17, 902-921. doi:10.1097/00005650-197909000-00003

[21] Helms, J.E., Henze, K.T., Sass, T.L. and Mifsud, V.A. (2006) Treating Cronbach's alpha reliability coefficients as data in counseling research. The Counseling Psychologist, 34, 630-660. doi:10.1177/0011000006288308

[22] Feldt, L.S., Steffen, M. and Gupta, N.C. (1985) A comparison of five methods for stimating the standard error of measuremente at specific score levels. Applied Psychological Measurement, 9, 351-361. doi: $10.1177 / 014662168500900402$

[23] Juniper, E.F., Guyatt, G.H. and Jaeschke, R. (1996) How to develop and validate a new health-related quality of life instrument. In: Spilker, B., Ed., Quality of Life and Pharmacoeconomics in Clinical Trials, 2nd Edition, Lippincott-Raven Publishers, Philadelphia, 49-56.

[24] Marinus, J., Leentjens, A.F.G., Visser, M., Stiggelbout, A.M. and van Hilten, J.J. (2002) Evaluation of the hospital anxiety and depression scale in patients with Parkinson's disease. Clinical Neuropharmacology, 25, 318-324. doi:10.1097/00002826-200211000-00008

[25] Armitage, P., Berry, G. and Matthews, J.N.S. (2002) Statistical methods in medical research. 4th Edition, Blackwell Publishing, Malden. doi:10.1002/9780470773666

[26] Clarke, D.E., Van Reekum, R., Patel, J., Simard, M., Gomez, E. and Streiner, D.L. (2007) An appraisal of the psychometric properties of the clinician version of the apathy evaluation scale (AES-C). International Journal of Methods in Psychiatric Research, 16, 97-110. doi:10.1002/mpr.207

[27] Reijnders, J.S.A.M., Ehrt, U., Lousberg, R., Aarsland, D. and Leentjens, A.F.G. (2009) The association between motor subtypes and psychopathology in Parkinson's disease. Parkinsonism and Related Disorders, 15, 379-382. doi:10.1016/j.parkreldis.2008.09.003

[28] Isella, V., Melzi, P., Grimaldi, M., Iurlaro, S., Piolti, R., Ferrarese, C., Frattola, L. and Appollonio, I. (2002) Clinical, neuropsychological, and morphometric correlates of apathy in Parkinson's disease. Movement Disorders, 17, 366-371. doi:10.1002/mds.10041

[29] Dujardin, K., Sockeel, P., Devos, D., Delliaux, M., Krystkowiak, P., Destée, A. and Defebvre, L. (2007) Characteristics of Apathy in Parkinson's disease. Movement Disorders, 22, 778-784. doi:10.1002/mds.21316

[30] Sockeel, P., Dujardin, K., Devos, D., Denéve, C., Destée, A. and Defebvre, L. (2006) The Lille apathy rating scale (LARS), a new instrument for detecting and quantifying apathy: Validation in Parkinson's disease. Journal of Neurology, Neurosurgery \& Psychiatry, 77, 579-586. doi:10.1136/jnnp.2005.075929 